\title{
Involuntary Childlessness at Work: Experiences of Emotion Work, Unfair Marginalization and Inadequacy'
}

I Mika Mård ${ }^{2}$

PhD, University Teacher, Åbo Akademi University, Department of Organization and Management, Finland

\begin{abstract}
This article presents and analyzes experiences of involuntary childlessness at work and, through that, attempts to increase our understanding of emotional and silenced experiences in organizations. While primarily being an exploratory study with a purpose to get an initial glimpse into working life through involuntary childless individuals' point of view, this article also engages with Arlie Hochschild's $(1979,1983)$ conceptualization of emotion work to analyze experiences of involuntary childlessness at work. The empirical data used in this paper are mainly collected through an anonymous diary studies method in Finland, and thematically presented in this article in three segments where three categories of emotion work related to involuntary childlessness are analyzed and discussed. In addition to offering an initial glimpse of involuntary childlessness at work, this paper hence contributes with a demonstration and analysis of the multifaceted emotion work related to these experiences.
\end{abstract}

\section{KEYWORDS}

Diary study / Emotion work / Identity work / Involuntary Childlessness / Marginalization

\section{Introduction}

hile disciplines interested in work life and organizational life have given some attention to issues related to the intersection of parenthood status and work-life, there are still features of this intersection that are fairly ignored. For example, while affective and embodied aspects of motherhood and pregnancy have received some amount of attention within these fields (see, e.g., Gatrell 2019; Haynes 2008; Turner \& Norwood 2013; van Amsterdam 2015), experiences of involuntary childlessness are rarely touched upon. Katila's (2019) article is, however, an exception to this, where she offers an affective and auto-ethnographic account of her experiences of infertility and menopause. In their paper on miscarriage-also partly an affective auto-ethnographic account-Boncori and Smith point out that 'the exposure of individuals' fragility is still taboo [...] within a culture that belittles or rejects the feminine, the emotional and the sensuous' $(2019$, p. 8), giving us a possible indication of why there is still a lack of attention given to a subject like involuntary childlessness. Although feminist scholars within organization studies have addressed some aspects of this belittlement, especially the tendency of positioning women's bodies 'as a threat or a danger to the spoken or unspoken social order of the organization

\footnotetext{
${ }^{1}$ You can find this text and its DOI at https://tidsskrift.dk/njwls/index.

${ }^{2}$ Corresponding author: Mika Mård, Faculty of Social Sciences, Business and Economics, Fänriksgatan 3B, 20500 Åbo, Finland. E-mail: Mika.Mard@abo.fi (ORCID: 0000-0002-9813-9240).
} 
on account of their "leakiness," unbounded-ness, unpredictability or unreliability' (Jack et al. 2019, p. 5) (see, also, Fotaki 2013; Gatrell 2019), the issue of involuntary childlessness is barely touched upon within this field.

However, there are some studies that give attention to the intersection of work life and childlessness (in a broad sense), but they vary greatly in terms of how childlessness is included or approached (see, e.g., Hamilton et al. 2006). Waumsley et al., for example, have touched upon the 'conflict between work and non-work experienced by people who do not live within a family structure that includes children' $(2010$, p. 3), while Grover (1991) investigated the perceived fairness of family-responsive policies in organizations from the perspectives of both parents and non-parents (see, also, Grover \& Crooker 1995). In their study on 'non-mothering identities within the academy' (2006, p. 24) Ramsay \& Letherby, on the other hand, approaches childlessness from an identity perspective, calling out 'the centrality of motherhood to feminine identity' (Kelly 2009, p. 171). While these studies provide some insight into the intersection of childlessness and work life they often approach childlessness in a broad sense, making no clear distinction between 'voluntarily' childlessness and 'involuntarily' childlessness. While I use single quotation marks here to highlight the problems of such a binary categorization-the reasons for childlessness are too diverse to be identified in two simple categories (see, e.g., Blackstone \& Stewart 2016) —it is a difference that illustrates a gap in research concerning work life and childlessness, that of a lack of attention given to involuntarily childlessness at work. Considering Boivin et al.'s (2007) estimation that over 72 million couples worldwide experience fertility problems, and that there arephenomenologically speaking-significant differences between voluntary childlessness (see, e.g., Blackstone and Stewart 2016; Kelly 2009; Park 2005) and involuntary childlessness (see, e.g., Letherby 1999), this gap is surprising.

The main purpose of the research done for this article was hence to do an empirically oriented, introductory and exploratory investigation into experiences of involuntary childlessness at work in Finland. It is important here to underline that 'the Nordic welfare states have a long tradition of extensive social policies directed at the family' (Rønsen 2004: 278). In addition to a tradition of generous family-responsive policies in the Nordic countries, like wage-compensated parental leave and publicly subsidized childcare, the political discourse within these countries also tend to frame declining fertility rates as a social and economic challenge (see, e.g., Rønsen 2004). This can add an unnecessary sociocultural shame or weight to involuntary childlessness, when childlessness becomes the deviation in a highly family-centered society and treated by policymakers as a socioeconomic challenge. However, it needs to be emphasized that both voluntary and involuntary childlessness is relatively common in the Nordic context, especially due to the trend of postponing childbirth to a higher age (see, e.g., Rønsen 2004). Childlessness is hence not-generally speaking - stigmatized in these societies, and people who suffer from involuntary childlessness can get help and support. Nonetheless, as Rich et al. (2011) reminds us, experiences of childlessness is always colored and pervaded by the broader sociocultural discourses, and this is-socio-politically speaking-a pronatalist context where work-family reconciliation policies are highly prioritized and the declining fertility rates is discursively constructed as a socioeconomic challenge.

Even though the broader socio-political context surely affects the overall experience of childlessness the main interest in this study is not to investigate childlessness as a social category, but rather to collect, demonstrate and analyze different lived experiences 
of involuntary childlessness at work per se. What kinds of experiences might an involuntary childless employee have during a normal day at work? However, the data collected in this research was noticeably permeated by colorful emotional components and intimate emotion work, and hence this article will especially focus on the emotional features of involuntary childlessness at work. In order to do that, this article will especially draw upon Hochschild's $(1979,1983)$ work on emotion management, but also demonstrate how the emotion work related to involuntary childlessness at work problematizes some of her conceptualizations.

\section{Emotion work}

When it comes to research on emotional life in organizations, Arlie Hochschild's work has surely had a tremendous influence (see, e.g., Fineman 2000; Zaph 2002). Her work on conceptualizing aspects of the intersection of social life and emotion management have been useful for this field (see, e.g., Callahan \& McCollum 2002), and will also be used here to shed a light on some of the emotional features of involuntary childlessness at work. This article will especially focus on her concepts of feeling rules and emotion work, since they draw attention to the emotional interplay in the intersection between the private and the social that the experiences illustrated later are colored by.

Any form of social interaction is directed by specific emotional 'scripts' that tell us the expected strength, duration and placement for our feelings and emotions. Arlie Hochschild $(1979,1983)$ coined the term feeling rules to conceptualize these rules and described them as 'the side of ideology that deals with emotion and feeling' (1979, p. 551), that is, 'a set of socially shared, albeit often latent (not thought about unless probed at), rules' $(1979$, p. 563). In simpler terms, these are rules that state what we should feel in certain social situations, that "we "should" or "shouldn't" feel this, we "have a right" or "don't have the right" to feel that' (Hochschild 1983, p. 69). Although some feeling rules are fairly universal, these rules are not fixed but vary over time and different social contexts. To illustrate this, Hochschild $(1979 ; 1983)$ points out that feeling rules are always rooted in our interpretative framework (ideology), something she calls framing rules: 'the rules according to which we ascribe definitions or meanings to situations' (Hochschild 1979, p. 566). Feeling rules, Hochschild (1979) argues, are always mutating according to changes in the patterns of framing rules, i.e., 'when an individual changes an ideological stance, he or she drops old rules and assumes new ones for reacting to situations, cognitively and emotively' (Hochschild 1979, p. 567).

However, we might not always experience the emotions a certain feeling rule stipulates, or we might experience 'wrong' emotions, and we have to work with, manage and regulate our misplaced feelings. Hochschild $(1979,1983)$ calls this emotion work, when the individual 'works on inducing or inhibiting feelings so as to render them "appropriate" to a situation' $(1979$, p. 551). In other words, emotion work refers to the work we have to put in when our feelings or emotions do not match a certain feeling rule and we have to try to change our emotional state in degree or quality. Hochschild makes an important clarification when she underlines 'that "emotion work" refers to the effortthe act of trying-and not to the outcome' (1979, p. 561). Emotion work, therefore, not only refers to the surface acting we do when we simply display the right feeling or emotion, but rather to the act of trying to change our inner feelings when we experience 
them as misplaced or inappropriate. Hochschild (1979) hence points out that emotion work is broader than the mere act of controlling, suppressing or preventing feelings: it also refers to the evoking or shaping of one's feelings and emotions.

Feeling rules and emotion work have received a lot of attention since Hochschild (1979, 1983) coined the terms (see, e.g., Zaph 2002), but her theories have also raised some clarifying critique. For example, Hochschild's theoretical framework has been criticized for some conceptual unclarity (see, e.g., Tonkens 2012), and that her framework inevitably portrays individuals as passive or 'crippled' actors (Bolton 2005). Allison (2017) also points out that many of Hochschild's ideas build upon a split between an inner 'real' self with authentic emotions and a 'false' self with inauthentic emotions produced by certain feeling rules, and argues that this conceptual distinction is not unproblematic and requires more critical engagement. Central to Hochschild's work is also a conceptual distinction between an individual's private life and a public life, which is perhaps most noticeable drawn in her distinction between emotional labor and emotion work: 'By "emotion work" I refer to the emotion management we do in private life; by "emotional labor" I refer to the emotion management we do for wage' (Hochschild 1990, p. 118). This distinction between private and public when it comes to emotional life is clearly noticeable throughout her work (see Callahan \& McCollum 2002). For example, as a response to The Managed Heart (1983), where Hochschild investigates the emotional requirements that certain occupational ideologies dictate, her intention in the Second Shift (1989) was-on the contrary-to draw attention to how 'we derive those feeling rules that apply to roles that are more diffuse and personal, like the role of husband and wife, man and woman' (Hochschild 1990, p. 118). In her own words, 'I moved from a focus on occupational roles, in which the ideology comes with the job to a focus on marital roles, in which partners bring with them similar or conflicting gender ideologies' (Hochschild 1990, p. 125).

Centrally imbedded in Hochschild's $(1979,1983,1990)$ work is hence a separation between the emotion management that relates to an occupational context (emotional labour) and the emotion management that relates to a person's private life (emotion work). In his commentary, Wouters (1989) heavily criticizes this conceptual distinction as 'artificial' and 'austere'. Wouters (1989) also argues that the private/public distinction in Hochschild's work is-in addition to being artificial-a morally laden dichotomy that restrain her to perceive and study it as a continuum. In this paper, I will use some of the concepts related to emotion management that Hochschild $(1979,1983)$ coinedespecially emotion work-because they are very helpful when describing, unfolding and illuminating certain aspects of experiences of involuntary childlessness at work. However, I will also draw upon the critique voiced by Wouters (1989), because the experiences analyzed in this paper are characterized by a kind of ('in-between') emotion work that challenges Hochschild's conceptual dichotomization between a private emotional life and a public emotional life.

\section{Method}

Exploring involuntary childlessness at work means, at least to some extent, doing research on a sensitive topic with vulnerable participants; therefore, it requires appropriate consideration when designing research methods. This was especially significant due to 
my phenomenological approach, meaning that the purpose of my research is to collect participants' subjective experiences and through a tradition of interpretative (hermeneutic) phenomenology analyze them in order to gain a deeper understanding of involuntary childless' everyday experiences at work. In order to capture the participants' lived and subjective experiences an anonymous open format diary study was used as the main method in this study (see, e.g., Bolger et al. 2003; Ohly et al. 2010). In addition to the diary study, a pilot interview was also conducted in order to get some initial insights (material used from this interview is referred to with the pseudonym Melissa). A diary study, Bolger et al. argue, is a very useful method when it comes to 'the investigation of phenomena as they unfold over time, or the focused examination of specific, and often rare, phenomena' (2003, p. 588). In addition to the latter being comparable to the purpose of this study-to collect and examine specific experiences that involuntary childless individuals encounter in their everyday lives at work-diary studies also carry the potential to capture and examine the complexity and richness of 'life as it is lived' through structured self-observation (Bolger et al. 2003). Reis and Gable hence describe this method as an 'everyday experience method' that can produce 'a detailed, accurate, and multifaceted portrait of social behavior embedded in its natural context' (2000, p. 190).

A support organization in Finland for people who experience fertility problems or undergo infertility treatments provided me with a platform to reach possible participants for this study. A letter containing information about the research and its method was posted on the organization's homepage and different Facebook groups in August 2018, which led to 17 women replying that they wanted to participate. A personal e-mail with more detailed information was sent to these participants, where I asked them to write a personal diary about their lived experiences of involuntary childlessness at work. I emphasized that the aim of the method was to let them freely describe their experiences, without limiting their diary entries with specific questions. I asked them to write accounts from their everyday lives at work during a four-month period (September-December 2018), but I also mentioned that they could write about past experiences related to involuntary childlessness at work if they chose to do so. Out of the initial 17 women, seven handed in their diaries, which varied in length from two to seven pages per diary. Some of the 10 initially interested participants who did not submit their diaries informed me later that they were not able to complete the task due to lack of time or the sensitive nature of the topic (the actual sharing of these kinds of experiences proved to be difficult). Given that the diaries that were handed in contained a broad variety of experiences, and rich descriptions thereof, I decided not to pursue material from these 10 interested participants after the four-month period had run out. Retrospectively, the advantage of the chosen method was clearly the detailed and rich descriptions of experiences related to involuntary childless at work, but the downside of this method was clearly the lack of interaction with the participants (they remained quite anonymous for me) and the subsequent difficulty in motivating more participants to write and submit their diaries.

While the dataset used in this article originates from a Finnish context, the participants work in different professions and are between 25 and 50 years old, making the dataset not anchored in one specific work-context or age-group. However, all participants are women, but instead of drawing any major conclusions it needs to be emphasized that I do not know who noticed my first posts about the research. Due to confidentiality reasons, I do neither have access to information about the gender of those visiting these 
sites, but my assumption is—based on visits to different forums on this webpage-that it is mostly visited by women. My own gender (male) might also have affected the number and composition of the participants, when some may experience it uncomfortable to share these experiences with a man. I have not revealed any information about my personal life (as childless), but since my name reveals my gender it might have had an effect. More importantly though, that some of the initially interested participants did not submit their diaries due to difficulties in writing about such a sensitive topic indicates that the chosen method might have excluded those who would prefer to share these experiences in person, but I also believe that the possibility to freely (without my immediate presence) write about these experiences might have motivated some to participate. It also needs to be addressed here that, since my interaction with the participants was established via a support organization, I assume that the main rationale for participating in this study was to 'make our voices heard'. This is an important characteristic of the data, when the experiences are described in a way that first and foremost showcases the participants' perspectives. However, while the perspectives of the employer, colleagues or parents are not included in the data, the main purpose of this study was to collect a wide variety of subjective experiences of involuntary childlessness at work.

The design of this study could be described as an open format diary study, where the participants are given a platform to freely write about their experiences of involuntary childlessness at work. This study is hence, empirically speaking, primarily exploratory in nature, with an initial purpose to illuminate our understanding of an understudied phenomenon. However, when thematically analyzing the data it became evident that while there are great variations in how these diaries were written, they are all permeated by different forms of emotional struggles and tensions. This article will hence especially focus on displaying different forms of emotion work in the diaries, but also later use these empirical fragments as instruments to discuss Hochschild's $(1979,1983)$ conceptual private/public dichotomization. In the analysis, especially three categories of experiences related to involuntary childlessness at work emerged, and while they have their own internal characteristics and relate to different features of work life they all include certain forms of emotion work. The following part of this paper will hence be divided into three distinct segments where these features of working life will be discussed from an involuntary childless' point of view.

\section{Childlessness and Emotion Work in Daily Interactions at Work}

It was so fucking difficult, sorry now [starts crying], it was so ... I was very happy for her, but at the same time ... I went to say congratulations, and that it's a very wonderful and beautiful baby, but I left the situation straight away, because I couldn't stay there. (Melissa) ${ }^{1}$

Hearing news about pregnancies, meeting co-workers' newborn babies or interacting with parents who are proud or deeply anxious over their children's endeavors are often inevitably features of work life. We will, in some way or another, be confronted with aspects of (new) parenthood at work, and all these interactions (as any other interaction as Hochschild $(1979 ; 1983)$ pointed out) are directed by specific emotional 'scripts' that tell us the expected strength, duration and placement for our feelings and emotion (reacting with a shrug would be outrageous). In the quote above, it is clear that Melissa

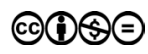


knows what is expected of her when meeting a co-worker's newborn baby. She knows that she should feel and express happiness and joy, and she is able to convey the right response for a short moment. However, as an involuntary childless with ongoing IVF treatments, Melissa do not only feel happiness in this interaction, but also a mixture of envy and sadness and clearly had to wrestle with the feeling rules in play here. What Melissa portrays here is a vivid example of Hochschild's $(1979,1983)$ description of emotion work, when she has to work with and manage her misplaced feelings in order for them to be 'appropriate' to the situation (1979, p. 551).

In most of the diaries collected for this study, some kind of emotion work due to situations when interacting with features of (new) parenthood at work was described. However, there were some differences in these experiences. For example, the following diary extract exemplifies how the interaction with (new) parenthood is experienced with total indifference, and how Maria had to induce her feelings so they were appropriate for the situation:

One of my students has recently become a grandparent and stayed after class to show me pictures of their ${ }^{2}$ grandchild on their phone. I didn't really know how to relate to the situation when the pictures didn't arouse any feelings in me. I got a little uncomfortable. I mainly thought to myself that this student is the same age as me and is already a grandparent, while I myself will never be in the same life situation as they are in now. I ended up just complimenting on how beautiful the pictures were and how beautiful the child was because that is how you are supposed to react in these situations. (Maria)

The emotion work portrayed here by Maria is somewhat different to what is portrayed earlier in this segment by Melissa, who had to inhibit her strong emotional response when meeting her co-worker's newborn baby. But since both Maria and Melissa were aware of the socio-moral feeling rules in play-they both know that they are not 'supposed to' feel this way-they reacted in quite a similar fashion, complimenting the baby and acting as they are supposed to. The form of emotion work that most often occurred in the diaries was, however, the act of trying to inhibit an overwhelming negative, or 'wrong', emotional response. Elina, for example, shared the following about a situation when she met her colleague's new-born child:

In that situation I got a really bad feeling because it was so concrete, it was so physical. Not when she was pregnant, that was nothing, but when the child in front of me was so physical, concrete and tangible, and I knew that this is once again someone else's. I probably got to the end of the workday but when I got home I was completely broken. It was so unpleasant, and joyful, at the same time (Elina)

When describing interactions with (new) parenthood Victoria even wrote about hating children at one point, exemplifying the degree of emotion work that might be needed for an involuntary childless person to render an initial emotional reaction 'appropriate' to the situation:

For a long time, I "hated children”- especially babies-I couldn't be near them. [I could] not admire how wonderful they are, etc., and [could] not listen to others talk about how wonderful their children/grandchildren are. But it feels like an expectation that I have to 
tolerate that. Many meetings have, for example, started with such baby talk. In the end, I quit a certain association just because of that phenomena. (Victoria)

Victoria demonstrates here that when interacting with (new) parenthood, the emotion work that is needed in order to act according to certain feeling rules can get so intense that it leads to leaving. Two other participants in this study also reported that they had either left a workplace or were considering leaving due to situations where the emotion work (due to involuntary childlessness) was too much to endure. Although leaving might seem like an extreme solution, it exemplifies the intense emotion work that an involuntary childless might experience in interactions with elements of (new) parenthood at work. An interesting aspect related to this form of emotion work was how it was often described in relation to certain spaces within the workplace.

\section{Emotion work and organizational space}

When analyzing the diaries, it became clear that the kind of emotion work described above was more concentrated to some spaces within the workplaces. Especially the coffee room occurred often since this is a space where employees can freely talk about their children and grandchildren, and was therefore a space wherein many of the participants wrestled with the kind of emotion work illustrated above. Maria also points out that this space makes her sometimes feel marginalized as involuntary childless:

During lunch, I often experience being outside the discussions when all my co-workers talk about their children and their doings. Sometimes I try to take part in the discussion by talking about similar experiences with my siblings' children, or then I start talking about something else with someone that I know is also childless. (Maria)

One of the participants also mentioned that there are often gym clothes, scout calendars, cookie jars or similar stuff for sale (to fundraise children's hobbies or school projects) in the coffee room at her workplace. She explained that this sometimes makes her feel uncomfortable as an involuntary childless, but she also pointed out that this gives her an opportunity to peak into the world of parenthood: 'What kind of mother would I be? I don't think I would have the energy to sell stuff like that to my co-workers, and I would not necessarily be as devoted a "soccer mom" as someone else' (Anna). Anna's reflection here highlights how the coffee room is a space where aspects of childhood and parenthood are often brought to the surface. The coffee room creates a space with windows into colleagues' lives outside of work, which also makes it a space where an involuntary childless might have to face their (involuntary) parenthood status and the emotions related to that. Another organizational space that occurred in the diaries was the restroom, but for an entirely different reason. The restroom was portrayed as a neutral space where one can escape the pressure of feeling rules and the requirement to manage and regulate one's misplaced feelings. Melissa explained that '[being childless] can cause moments at work [of] terrible emotional burst and outburst of tears.' In these situations, Melissa explains; 'I just have to say 'I'm sorry, I'll have to go the restroom, but I will be back soon".' For Melissa, the restroom is like 
a free-zone where she can let out the feelings and emotions she actually feels. Looking at organizational space through the participants' descriptions above indicates that feeling rules and emotion work are never disconnected from organizational space. Spaces we use at work are related to different feeling rules and hence require their own forms of emotion work.

Summing up, this segment has focused on emotion work that participants in this study portrayed as embedded in social interactions with elements of (new) parenthood at work. It has been demonstrated here that everyday social interactions at work may for an involuntary childless person cause difficult emotional reactions that $\mathrm{s} / \mathrm{he}$ needs to 'work with' in different ways; sometimes the participants in this study had to induce certain feelings and sometimes they had to inhibit them. Here Hochschild's description of emotion work, when a subject has to 'manage and regulate their misplaced feelings so as to render them "appropriate" to a situation' (1979, p. 551), is a very suitable tool to capture the experiences described in this segment. However, this segment has also demonstrated the interplay between emotion work and organizational space, that certain feeling rules and certain forms of emotion work can be more concentrated to some spaces within the workplaces than others.

\section{Childlessness and Emotion Work in Processes of Organizing Work}

"I am sorry that I can't invest in this job the same way as you can because I have children. I hope you understand that." This is what one of my co-workers said to me. I couldn't respond to it in any way. My understanding was that she defended her refusal to do certain job tasks with the argument that she has children. I would, accordingly, have more resources to do less appealing work tasks than she has. I didn't dare argue about it or say against her because childlessness is such a painful thing for me. (Paula)

The participants in this study often described how processes of organizing work may cause differences in parenthood status to surface, and how they-as childless employeesoften experienced a sense unfair marginalization when it comes to issues related to daily organizing of work. For example, in the extract above, Paula demonstrates how the difference in parenthood status was used against her when assessing and agreeing upon who does what in the workplace. Another participant also described a similar situation: 'My experience is that supervisors let parents "off the hook" because they have stressful lives outside of work, and hence childless employees have to take on more tasks and responsibility at work' (Jennie). Most often, however, the participants in this study described how their status as non-parent was to their disadvantage when assessing and agreeing upon who works when:

I have also experienced a certain inequality when it comes to shift work. In our three-shift work [nursing], night shifts are always given to childless employees, while parents get to do more evening and day shifts. This, I feel, is unfair. Everyone who gets a permanent position in our department knows that we work in three shifts. Mothers justify their need for certain shifts with the opening hours of daycare centers. This irritates me. (Jennie) 
Differences in utilizing flexible arrangements at work was also an often-occurring emotionally laden theme in the diaries, most often due to experiences of unfairness and inequality concerning the entitlement for utilizing flexibility, as illustrated by Sofia:

Often, employees with children draw upon the fact that they have to leave work earlier because their child is alone, because of a parent meeting or because of the child's hobby, etc. ... Often, these employees who have children receive advantages, while non-parents are not taken into account.... And it has been said straight to my face that since you don't have any children, and hence nothing extra to do, maybe you can do my evening shift. (Sofia)

Although Sofia demonstrates an understanding that being a parent sometimes requires flexibility to take care of a sick child or plan according to a child's needs, there is a tangible feeling of unfair marginalization that comes through in these diary extracts. There is especially a tone of unfairness due to the expectation that a childless employee should be able to take care of extra work. 'I am fully aware of the situation and understand it, but still ... dammit!', another participant uttered when describing a similar situation. These feelings of unfairness were, however, most often described in relation to situations when parents' needs for flexibility was recognized over non-parents' needs for flexibility. Sofia, for example, revealed that the prime cause for her feelings of unfairness was due to the entitled normalcy that parents' need for flexibility had become in her organization, while her requests for flexibility was questioned because she was childless. Children, she explained, had become an unquestionable, 'legitimate' reason to utilize flexibility at work, while her 'doctor's appointments had to be planned in such a way that it would not affect the work' (Sofia). Preferential flexibility for parents over non-parents was a recurring theme in the descriptions about experiences of unfairness concerning flexibility in work scheduling. Hence, the experiences of unfairness related to flexibility that the participants reported in this study are not primarily about differences in the extent to which flexibility is utilized, but rather about unequal entitlement to utilize flexibility.

Fairness in relation to differences in parenthood status in organizations has captured some scholarly interest, especially that of perceived fairness regarding family-responsive policies in organizations (see, e.g., Seijts 2002). Research has indicated that employees who benefit from family-responsive policies perceive these policies to a greater extent as fair than those who do not benefit or do not identify with does who do (see, e.g., Grover 1991, p. 251). However, while examining the impact of family-responsive policies on work commitment, Grover and Crooker found that people are usually more committed to organizations that offer family-friendly policies, 'regardless of the extent to which the people might personally benefit from the policies' (1995, p. 283). So, while research shows family-friendly policies can have an overall positive affect on organizational commitment regardless of parenthood status (Grover \& Crooker 1995), there is also research that indicate differences in how family-responsive policies in organizations are perceived between parents and non-parents (see, e.g., Grover 1991). These studies are, however, mainly concerned with perceived fairness of formal organizational policies, that is, the focus is on the relationship between the employee and the organization. While this is important, it fails to recognize the emotion work that might be involved when these policies are played out in practice, often in everyday interactions with co-workers and supervisors. In the extracts above Paula portrays how a simple issue of organizing work can stir up a very 'painful thing' for her if it's done on the basis of a distinction between 
parents and non-parents, while Jennie is clearly irritated over the unfair distribution of shifts between parents and non-parents. In other words, the organizing of work (e.g., scheduling of vacation, distribution of shifts or flexible hours) can stir up strong feelings of irritation, tension and unfairness for an (involuntary) childless, feelings that needs to be inhibited because they are not supposed to be aired. But, analyzing these experiences beyond the surface-level also shows that there is a complex emotion work related to these experiences, when the same feeling that is caused by an unfair situation also becomes the barrier to speak up.

\section{The 'catch 22' of vacation scheduling}

Every time we receive the vacation lists, the separation between non-parents and parents begins. (Sofia)

Planning and scheduling vacations are often a collective endeavor in the organization, i.e., it is done in close collaboration and agreement with co-workers and managers. This practice was an often-occurring cause of feelings of unfair marginalization for the participants in this study, especially when it came to scheduling vacation during school breaks: 'Parents easily get vacation during winter break or autumn break ${ }^{3}$ without a grumble, but if a childless employee asks for vacation during, e.g., autumn break it is questioned' (Jennie). 'It feels like, if you have children, you get vacation easier when schools have their break periods', another participant stated. There is a certain tone of unfairness that seeps through here, and some of the participants reported that the sense of unfairness is especially tangible during holidays like Christmas, New Year's and Easter. In addition to feelings of unfair marginalization when planning and scheduling vacation, many of the diary entries were also permeated by a 'catch 22 ' situation, as captured in the following extract:

'I also want vacation then, but do I have the right to require that when you have a family and I do not? Am I like ... well ... if it is more important for you than me' (Melissa).

It is noticeable here that Melissa, as a childless employee, sees herself in a weaker position when it comes to negotiating time for vacation, and she recognizes her ambiguous feelings about whether she has the right to require what she wants. The reason for this inferior position, Melissa later implied, is that, in addition to understanding parents' need for vacation during school breaks, the process of planning and scheduling vacation with co-workers and managers is often a painful reminder of her situation as involuntary childless. So, even though she would want to negotiate for vacation during a certain time of the year-and having the same right to do so-this process touches upon something vulnerable and painful for her, making her forfeit her wishes in order to get out of the situation. In the following diary extracts it is also noticeable that, in addition to feelings of being marginalized in processes of planning and scheduling of vacation, this process also touches upon something vulnerable and painful for these participants:

Often, the parents request that they have to have vacation when their children have school breaks because where are they to put their children if they don't get vacation? And it is 
directly communicated: 'You don't have children, so I guess you have not planned to be on vacation?' [...] And, of course, you get a bad feeling when it is being said to you that you don't need vacation at a certain time when you don't have children. This vacation thing causes a lot of unfairness, conflict and disputes between employees. (Sofia)

My manager asked if I could do more work during winter breaks because the other ones (with families) want to be on vacation. I agreed, although it was irritating. My husband has a son who is also on break then. I felt that $I$, as one who suffers from infertility, am completely marginalized. (Anna)

Since planning and scheduling vacation is often a collective endeavor within the organization, this process might inevitably create tensions between employees with different parenthood status. The two diary extracts above demonstrate two central features in the participants' descriptions of experiences related to this. The first one being that vacation planning can cause feelings of unfair marginalization for non-parents, when parents (understandably) request vacation during certain times of the year. The second feature is that these experiences are colored by feelings of inferiority, which makes it difficult for the involuntary childless to contest this marginalization, creating a 'catch 22' situation. As suggested above, this 'catch 22' situation can be better comprehended by understanding that the process of planning and scheduling vacation, and the sense of marginalization that this might cause, can be a painful reminder of an unwanted situation for an involuntary childless. It might touch upon something vulnerable, even painful, giving them the sense that they are in a weaker position to negotiate and require vacation during certain times of the year.

Summing up, this segment has focused on processes of organizing work (e.g., scheduling of vacation, distribution of shifts or flexible hours) and demonstrated that these processes can stir up feelings of irritation, tension and unfairness for an (involuntary) childless. This, one can assume, is probably not only limited to involuntary childlessness, but can also be an issue for any non-parent. But, in addition to the emotion work embedded in these processes (i.e., when the subject has to inhibit these feelings), this segment has also highlighted that there is a complex form of emotion work related to these experiences. The feelings of irritation or unfairness was often described in the data as accompanied with a painful reminder of an involuntary parenthood-status, evoking a sense of being inferior to the other (parents) in the negotiations. This emotion work has here been described as a 'catch 22' situation, when the feelings that is caused by an unfair situation also becomes the barrier to speak up.

\section{Childlessness and Emotion Work in relation to Identity Work}

I was single for a few years when I suddenly got pregnant from a romance, but I had a miscarriage (in the $9^{\text {th }}$ week). That was a difficult time but somehow the "happiest" in my life as a woman. I was at least, for a while, "a real woman" [...] The last two decades I have pondered whether women without children suffer from burnout more often than women with children. I've had to seek justification for my existence through work. When I don't have children I'm not a "real woman"-I have not fulfilled my duty. I hence have to fill my life with work. ... But I will never, no matter how much I fill my days by immersing myself in work, become a complete woman. (Victoria) 
In the extract above, we can see how Victoria describes her involuntary childlessness as something that disturbs and unsettles her perceived identity of a 'complete woman'. Victoria's account demonstrates here, first of all, that in 'pronatalist ideologies, "woman" and "mother" can often be presented as synonymous identities and experiences' (Rich et al. 2011, p. 232). Secondly, and more importantly, it demonstrates that involuntary childlessness can cause feelings of inadequacy in the subject's identity work. The concept of identity work (instead of identity) is used here to emphasize that Victoria's account above is a demonstration of the sometimes ambiguous and contradicting nature of self-perception, when 'identities, or subjectivities, are caught up in contradictions and struggles, tension, fragmentation and discord' (Watson 2008, p. 123). Instead of seeing identities as fixed, or static, categorizations that can be achieved, identity work emphasizes the continuously on-going project (or work) 'of forming, repairing, maintaining, strengthening or revising the constructions that are productive of a sense of coherence and distinctiveness' (Sveningsson \& Alvesson 2003, p. 1165). The concept of identity work hence highlights the struggles in Victoria's account of becoming (note: not being) a 'real woman', that is, that identity is a continuous work in progress that takes place between competing discourses and multiple identities (see, Sveningsson \& Alvesson 2003; Watson 2008).

The emotionally laden nature of her identity work is particularly tangible in Victoria's account, especially a strong sense of defectiveness or inadequacy in relation to the identity of 'a real woman'. Kristeva's (1982, p. 5) work on abjection might be useful in order to illustrate the emotion work involved here. Kristeva points out that when a subject identifies with something outside, but is hindered by something within him/herself, it might 'pulverize the subject' $(1982$, p. 5). In other words, since it is her own being (involuntary childless) that disturbs and unsettles Victoria's identity work in becoming a 'complete' woman, the feeling of inadequacy that Victoria portrays above needs to be understood as accompanied with feelings of existential struggles and tensions. Some of the diaries collected for this study contained similar descriptions of inadequacies in identity work related to certain professional identities, i.e., descriptions of involuntary childlessness being experienced a something that disturbs certain notions of professional identities. These descriptions were often accompanied by feelings of professional inadequacy and difficult existential questions concerning the Self, emphasizing that emotion work due to involuntary childlessness can also be caused by perceptions, stereotypes and expectations related to one's professional identity.

\section{Childlessness and feelings of professional inadequacy}

Some of the participants in this study disclosed a challenging tension between being childless and their professional identities. Professional identity refers here to the various meanings, attributes, beliefs and values that are attached to, or associated with, a profession by oneself and others (see Slay \& Smith 2011; Ibarra 1999). One's professional identity might not, however, always be easily aligned with one's other identities, forcing the subject to constantly renegotiate its position in relation to ideals related to one's profession (see, e.g., Watson, 2008). Drawing upon the concept of identity work, professional identities are here not seen as static positions, but rather seen as continuous projects 'constituted through the interplay of emotions, discourse and identity work' (Ahuja et al. 2019, p. 3). Haynes (2008) has, for example, explored 
the frictions of interacting the identity of motherhood with professional identities within accounting, while Turner and Norwood (2013) have demonstrated the challenges of combining the (embodied) identities of both a 'good mother' and a 'good worker'. The participants in this study who worked within the field of early childhood education often mentioned, in quite a similar fashion, a tension between their identity as childless and the professional identity of a (kindergarten) teacher, which they experienced as closely associated with attributes of motherhood. In a very emotional state, Melissa explained that she as an involuntary childless had to wrestle with some difficult questions related to her professional identity and her dream of working as a kindergarten teacher:

I started to question my own identity and my work identity, that ... can I work in this profession if I'm not a mother? It is this stereotype again that it is expected.... Even during my education, we were told that when you are parents, when you are mothers, fathers, caretakers, then you will understand these things differently. [...] I started to ponder these things a lot... Can I be a good kindergarten teacher if I'm not a mother? That was awful. I had a crisis during several months for that. (Melissa)

Here, Melissa portrays strong feelings of inadequacy, rooted in the notion that childlessness is an infringement upon the various meanings and attributes-or what she calls stereotypes-that are attached to her profession. It needs to be emphasized here that Melissa's sense of inadequacy, due to attributes of parenthood being attached to the professional identity of a kindergarten teacher, should not simply be interpreted as a personal or intra-subjective battle. Instead, it indicates and reminds us that childlessness is 'both experienced within, and pervaded by, broader sociocultural discourses,' as Rich et al. (2011, p. 226) put it. In the following extracts-where participants disclose similar feelings of inadequacies in their professional identities due to childlessness-one can notice how it is the social environment that causes this sense of inadequacy. In other words, the close relationship between the notion of motherhood and the professional identity of a teacher or kindergarten teacher-and that childlessness is therefore an infringement-is underscored by others:

During a fieldwork when I was studying to become a teacher, I had to have a meeting with a mother about her child's homework assignments. The mother snarled at me: "You don't have any children of your own, so don't come here and teach me how to raise my child!" The exact phrasing might have been different, but that was the content. This was the first time I understood that I was incomplete as a person, as a woman, as a teacher. Even though reason told me otherwise, the feeling stayed. I was about 30 years old at the time. If I'm not a mother, I am not a suitable teacher. And not a woman. (Victoria)

When I was at my previous workplace and my work career had just started, I had, in some situations, this feeling that others insinuated that I do not know anything about life/teaching when I don't have children. I can't remember any concrete situation, but I remember that I was thinking that. (Maria)

Being a teacher or kindergarten teacher can in itself cause difficult emotion work while struggling with involuntary childlessness. Melissa voiced that even though she likes children a lot, 'I was sometimes very anxious to go there and meet the children, meet the 
parents, meet the children's problem and meet my own problems'. Additionally, as illustrated above, involuntary childlessness—and non-parenthood overall—can cause feelings of inadequacy due to certain sociocultural attributes attached to these professions. However, in a context permeated with these kinds of framing rules (i.e., a close relationship between the notion of motherhood and the professional identity of a teacher or kindergarten teacher), these feelings of inadequacies are not supposed to be voiced, it is something the childless has to constrain and 'work' with internally.

The main purpose of this segment is, hence, to point out that involuntary childlessness may cause tensions, struggles and feelings of inadequacy in relation to certain professional identities, causing existential identity work that is accompanied with demanding internal emotional struggles. In order to comprehend the emotional side to this identity work, I want to argue that Kristeva's (1982) notion of abjection can be used to shed some light on this, i.e., when childlessness is experienced as a 'feature' that disturbs the subjects' attempt to establish a certain professional identity and sense of self (see, also, Rizq 2013). But, and importantly, it is their own involuntary parenthood status-something that they can't simply distance themselves from-that causes these feelings of professional inadequacy. Abjection, Kristeva points out, is at the peak of its strength when the subject attempts to identify with something but finds the impossible within; 'when it finds that the impossible constitutes its very being' (1982, p. 5). This, I argue, can be used as a lens to comprehend the diary extracts above, i.e., these extracts illustrate the anxious experience of abjection when their very own being (involuntary childless) constitutes that very thing that disturbs and unsettles a certain professional identity or sense of self. This experience can, Kristeva's (1982) points out, pulverize the subject, highlighting the complex emotion work involved when the subject has to work on inhibiting these emotions.

\section{Conclusion}

That some of us have children and some of us not, is an undeniable actuality that permeates many of our daily interactions at work. But, it is still something that is barely touched upon in fields of research related to organizational life and work life, especially when not having a child is involuntary (see, however, Katila 2019; Boncori \& Smith 2019). Differences in parenthood status often remain hidden under the surface of the formal sides to organizations, but it still—as demonstrated in this paper-greatly affects life at work. The purpose of this article has been to respond to the lack of attention given to involuntary childlessness at work by doing an empirically oriented, introductory and exploratory investigation into this terrain, i.e., to collect, give a voice to and analyze involuntary childless individuals' experiences at work. However, it is important to stress that the data collected for this study originates from Finland, and hence only sheds a light on this issue in a Nordic working life context. Here, I hence want to emphasize the need to also explore this issue in other contexts. Also, this article has especially explored the disenfranchised emotion work related to three features of life at work: daily interactions, the organizing of work and identity work. These do not cover all the features of childless employees' lives at work, and therefore I want to emphasize the necessity for future research that investigates this topic more broadly, but also explores each category of experiences more in depth. 
In my analysis of the collected experiences of involuntary childlessness at work, this paper has drawn upon Hochschild's $(1979,1983)$ work on emotion management and demonstrated that it can be useful to capture some of the emotional features of involuntary childlessness at work, especially the struggles of working with emotional dissonance-when the emotions actually felt do not match with the emotions that according to certain feeling rules should (or should not) be publicly expressed. However, these same experiences demonstrate that Hochschild's (ibid.) conceptual dichotomization between a private and public life can be misleading. This distinction is a conceptual oversimplification that overlooks the kind of 'in-between' emotion work that the diary extracts exemplify above, where emotional features, systems or experiences of the subject's private life are (re)surfaced and becomes blurred and intertwined with the subject's public life at work. As we have seen above, the emotional weight of involuntary childlessness is not left outside the doors to the workplace, but often managed and worked with in obscure at work. The key point here is that the conceptual divide between private and public that is evident in Hochschild's (1983) work do not do justice to this form of mobility of emotional life, and that giving attention to the affective characteristics of the intersection of work life and involuntary childlessness actively challenges the use of this distinction in studying emotional life. In other words, emotion work related to involuntary childlessness at work demonstrates that the way we respond to situations at work can be colored by events, emotions and emotional patterns formed in lives outside work, and this form of mobility of emotional life challenges Hochschild's (1979; 1983) clear-cut conceptual dichotomy between a subject's private and public lives. So, in addition to contributing with an initial exploration of involuntary childlessness at work, this article also contributes with a critique of this conceptual dichotomization when studying emotional life. The affective experiences of involuntary childlessness at work contributes, in other words, with an example of 'in-between' emotion work that this conceptual dichotomy does not sufficiently manage to capture.

Some of the experiences of involuntary childlessness at work demonstrated in this paper are colored with (sometimes heartbreaking) outbursts of disenfranchised emotional distress, feelings of marginalization and inadequacy. Frost et al. point out that 'we cannot fully see organizations until we allow people to speak the unspoken reality of suffering' (2006, p. 843), and that while organizational 'policies can sometimes lessen or alleviate pain, compassion can help to make a heavy burden of suffering more bearable' (2006, p. 843). Even a small act of compassion, Frost et al. emphasize, can 'help the sufferer reconnect to his or her workplace and feel valued' (2006, p. 850). By shedding light on some of these unspoken realities in organization, this paper has also-in part-aimed to implicitly underline the value of compassion. Compassion has the potential to-at least momentarily-lighten the burdens of hidden emotion work that involuntary childlessness may sometimes cause at work.

\section{Acknowledgments}

Part of this research was supported by funding from the Academy of Finland [grant number: 298370]. 


\section{References}

Ahuja, S., Heizmann, H., \& Clegg, S. (2019). Emotions and identity work: Emotions as discursive resources in the constitution of junior professionals' identities, Human Relations 72(5): 988-1009. doi: https://doi.org/10.1177/0018726718785719.

Allison, M. (2017). Overcoming Arlie Hochschild's concepts of the 'real' and 'false' self by drawing on Pierre Bourdieu's concept of habitus, Emotion, Space and Society 23: 9-15. doi: https://doi.org/10.1016/j.emospa.2017.01.003.

Blackstone, A., \& Stewart, M. D. (2016). "There's more thinking to decide": How the childfree decide not to parent, The Family Journal 24(3): 296-303. doi: https://doi. org/10.1177/1066480716648676.

Boivin, J., Bunting, L., Collins, J. A., \& Nygren, K. G. (2007). International estimates of infertility prevalence and treatment-seeking: Potential need and demand for infertility medical care, Human Reproduction 22(6): 1506-1512. doi: https:/doi.org/10.1093/humrep/ dem046.

Bolger, N., Davis, A., \& Rafaeli, E. (2003). Diary methods: Capturing life as it is lived, Annual Review of Psychology 54: 579-616. doi: https://doi.org/10.1146/annurev. psych.54.101601.145030.

Bolton, S. J. (2005). Emotion Management in the Workplace, New York: Palgrave.

Boncori, I., \& Smith, C. (2019). I lost my baby today: Embodied writing and learning in organizations, Management Learning 50(1): 74-86. doi: https://doi.org/10.1177/ 1350507618784555.

Callahan, J. \& McCollum, E. (2002). Obscured variability: The distinction between emotion work and emotional labor. In N. Ashkanasy, W. Zerbe \& C. Härtel (eds.) Managing Emotions in the Workplace, Armonk, NY: M.E. Sharpe Inc., pp. 219-231.

Fineman, S. (2000). Emotion in Organization, London, Thousand Oaks, New Delhi: Sage Publications.

Fotaki, M. (2013). No woman is like a man (in academia): The masculine symbolic order and the unwanted female body, Organization Studies 34(9): 1251-1275. doi: https://doi. org $/ 10.1177 / 0170840613483658$.

Frost, P., Dutton, J. E., Maitlis, S., Lilius, J., Kanov, J., \& Worline, M. (2006). Seeing organizations differently: Three lenses on compassion. In C. Hardy, S. Clegg, T. Lawrence, \& W. Nord (eds.) The SAGE Handbook of Organization Studies, $2^{\text {nd }}$ ed., London: Sage Publications, pp. 843-866.

Gatrell, C. (2019). Boundary creatures? Employed, breastfeeding mothers and 'abjection as practice', Organization Studies 40(3): 421-442. doi: https://doi.org/10.1177/ 0170840617736932.

Grover, S. L. (1991). Predicting the perceived fairness of parental leave policies. Journal of Applied Psychology, 76(2): 247-255. doi: http://dx.doi.org/10.1037/0021-9010.76.2.247.

Grover, S. L., \& Crooker K. J. (1995). Who appreciates family-responsive human resources policies: The impact of family friendly policies on the organizational attachment of parents and non-parents, Personnel Psychology 48(2): 271-288. doi: https://doi.org/ 10.1111/j.1744-6570.1995.tb01757.x.

Hamilton, E. A., Gordon, J. R., \& Whelan-Berry, K. S. (2006). Understanding the worklife conflict of never-married women without children, Women in Management Review 21(5): 393-415. doi: https://doi.org/10.1108/09649420610676208.

Haynes, K. (2008). Transforming identities: Accounting professionals and the transition to motherhood, Critical Perspectives on Accounting 19(5): 620-642. doi: https://doi.org/ 10.1016/j.cpa.2006.10.003.

Hochschild, A. R. (2012 [1983]). The Managed Heart. Commercialization of Human Feelings, Berkeley: University of California Press. 
Hochschild, A. R. (1979). Emotion work, feeling rules, and social structure, American Journal of Sociology, 85(3): 551-575. doi: https://www.jstor.org/stable/2778583.

Hochschild, A.R. (1990). Ideology and emotion management: A perspective and path for future research. In T.D Kemper (ed.) Research Agendas in the Sociology of Emotions, Albany: SUNY Press, pp. 117-142.

Ibarra, H. (1999). Provisional selves: Experimenting with image and identity in professional adaptation, Administrative Science Quarterly 44(4): 764-791. doi: http://dx.doi.org/ $10.2307 / 2667055$.

Jack, G., Riach, K., \& Bariola, E. (2019). Temporality and gendered agency: Menopausal subjectivities in women's work, Human Relations 72(1): 122-143. doi: https://doi.org/ $10.1177 / 0018726718767739$.

Katila, S. (2019). The mothers in me, Management Learning 50(1): 129-140. doi: https://doi. org/10.1177/1350507618780653.

Kelly, M. (2009). Women's voluntary childlessness: a radical rejection of motherhood?, Women's Studies Quarterly 37(3/4): 157-172. doi: https://www.jstor.org/stable/27740584.

Kristeva, J. (1982). Powers of Horror: An Essay on Abjection, New York: Columbia University Press.

Letherby, G. (1999). Other than mother and mothers as others: The experience of motherhood and non-motherhood in relation to 'infertility' and 'involuntary childlessness', Women's Studies International Forum 22(3): 359-372. doi: https://doi.org/10.1016/ S0277-5395(99)00028-X.

Ohly, S., Sonnentag, S., Niessen, C., \& Zapf, D. (2010). Diary studies in organizational research, Journal of Personnel Psychology 9(2): 79-93. doi: https://doi.org/10.1027/18665888/a000009.

Park, K. (2005). Choosing childlessness: Weber's typology of action and motives of the voluntarily childless, Sociological Inquiry 75(3): 372-402. doi: https://doi.org/10.1111/j.1475682X.2005.00127.x.

Ramsay, K. \& Letherby, G. (2006). The experience of academic non-mothers in the gendered university, Gender, Work \& Organization 13(1): 25-44. doi: https://doi.org/10.1111/ j.1468-0432.2006.00294.x.

Reis, H. T., \& Gable, S. L. (2000). Event-sampling and other methods for studying everyday experience. In H. T. Reis \& C. M. Judd (eds.), Handbook of Research Methods in Social and Personality Psychology, New York: Cambridge University Press, pp. 190-222.

Rich, S., Taket, A., \& Graham, M. (2011). 'Unnatural', 'unwomanly', 'uncreditable' and 'undervalued': The significance of being a childless woman in Australian society, Gender Issues 28(4): 226-247.

Rizq, R. (2013). States of abjection, Organization studies 34(9): 1277-1297. doi: https://doi. org/10.1177/0170840613477640.

Rønsen, M. (2004). Fertility and family policy in Norway-A reflection on trends and possible connections, Demographic Research 10(10): 265-286. doi: https://oi.org/10.4054/ DemRes.2004.10.10.

Seijts, G. H. (2002). Milking the organization? The effect of breastfeeding accommodation on perceived fairness and organizational attractiveness, Journal of Business Ethics 40(1): 1-13. doi: https://www.jstor.org/stable/25074859.

Slay, H. S., \& Smith, D. A. (2011). Professional identity construction: Using narrative to understand the negotiation of professional and stigmatized cultural identities, Human Relations 64(1): 85-107. doi: https://doi.org/10.1177/0018726710384290.

Sveningsson, S. \& Alvesson, M. (2003). Managing managerial identities: Organizational fragmentation, discourse and identity struggle, Human Relations 56(10): 1163-93. doi: $10.1177 / 00187267035610001$. 
Tonkens, E. (2012). Working with Arlie Hochschild: Connecting feelings to social change, Social Politics: International Studies in Gender, State \& Society 19(2): 194-218. doi: https://doi.org/10.1093/sp/jxs003.

Turner, P. K., \& Norwood, K. (2013). Unbounded motherhood: Embodying a good working mother identity, Management Communication Quarterly 27(3): 396-424. doi: https:// doi.org/10.1177/0893318913491461.

van Amsterdam, N. (2015). Othering the 'leaky body': An autoethnographic story about expressing breast milk in the workplace, Culture and Organization 21(3): 269-287. doi: https://doi.org/10.1080/14759551.2014.887081.

Watson, T. J. (2008). Managing identity: Identity work, personal predicaments and structural circumstances, Organization 15(1):121-143. doi: https://doi.org/10.1177/1350508407084488.

Waumsley, J. A., Houston, D. M., \& Marks, G. (2010). What about us? Measuring the worklife balance of people who do not have children, Review of European studies 2(2): 3-17.

Wouters, C. (1989). The sociology of emotions and flight attendants: Hochschild's Managed Heart, Theory, Culture \& Society 6(1): 95-123. doi: https://oi.org/10.1177/ 026327689006001005.

Zaph, D. (2002). Emotion work and psychological well-being. A review of the literature and some conceptual considerations, Human Resource Management Review 12(2): 237-268. doi: https://doi.org/10.1016/S1053-4822(02)00048-7.

\section{Notes}

${ }^{1}$ All the quotes are freely translated from Finnish.

${ }^{2}$ My respondent used the gender-neutral pronoun hän here, making the gender of the person my informant is talking about unknown.

${ }^{3}$ Schools in Finland have a one-week winter break in February-March and 3-5 days of autumn break in mid-October. 